\title{
DISCURSO DA SALA DE AULA DE LÍNGUA ESTRANGEIRA: DIALOGICIDADE INTER-REGULADA
}

\author{
Jader Martins Rodrigues Junior* \\ Universidade Federal do Ceará \\ Centro de Humanidades \\ Fortaleza, CE, Brasil
}

\author{
Izabel Magalhães ** \\ Universidade Federal do Ceará \\ Departamento de Letras Vernáculas \\ Fortaleza, CE, Brasil \\ Universidade de Brasília \\ Brasília, DF, Brasil
}

\begin{abstract}
Resumo: O presente trabalho tem como objetivo analisar o discurso em uma sala de aula de nível iniciante em escola de língua estrangeira. Para tanto, apresentamos uma breve revisão do conceito de discurso (FOUCAULT, 1996, 2008; FAIRCLOUGH, 2003, 2010; MAINGUENEAU, 2008), também abordando os conceitos do dialogismo bakhtiniano (2011) e da interincompreensão regulada de Maingueneau (2008). Nessa esteira adotamos, em nossa metodologia de análise, a teoria social do discurso (FAIRCLOUGH, 2001), bem como as considerações de Blommaert (2005) sobre a natureza dialógica da comunicação. Dessa forma, pretendemos estabelecer a ancoragem teórico-metodológica que norteia nossa análise das amostras de eventos comunicativos. Como resultado da análise, concluímos que as relações interdiscursivas que se realizam nessa sala de aula são controladas entre os participantes da interação, conforme as metas estabelecidas no programa do curso, gerando uma dialogicidade inter-regulada de acordo com o plano de ensino.
\end{abstract}

Palavras-chave: Discurso. Dialogismo. Sala de aula. Língua estrangeira.

1 INTRODUÇÃO

Considerando a natureza dialógica da comunicação e a perspectiva da prática discursiva socialmente situada, tencionamos no presente artigo analisar o discurso de uma sala de aula de nível iniciante em língua inglesa, bem como amostras de eventos nos quais a língua estrangeira se faz presente fora da sala de aula, com o objetivo de

\footnotetext{
* Mestre em Linguística Aplicada pela Universidade Estadual do Ceará. Professor de língua inglesa. Email: jaderrodrigues@ufc.br.

** Doutora em Linguística pela Lancaster University, Reino Unido, com Pós-Doutorado na mesma instituição. E-mail: mizabel@uol.com.br.
} 
compreender as relações dialógicas que se realizam nos usos socialmente situados da língua e as perspectivas que podem ser geradas dessas práticas discursivas. Para isso, apresentamos nas próximas seções uma breve revisão do conceito de discurso (FOUCAULT, 1996, 2008; FAIRCLOUGH, 2003, 2010; MAINGUENEAU, 2008), associado à noção do dialogismo bakhtiniano, e da concepção de interincompreensão regulada (MAINGUENEAU, 2008). Como forma de problematizar o tema em estudo, apresentamos também uma breve discussão da perspectiva de Blommaert (2005) sobre a natureza dialógica da comunicação, para, em seguida, passar à análise dos dados coletados e gerados em uma pesquisa realizada no ano de 2012, com base na teoria social do discurso de Fairclough $(2001,2003)$ e na perspectiva sociodiscursiva de Blommaert (2005). Nesse sentido, buscamos resposta às seguintes questões em nosso estudo: (a) qual a perspectiva que orienta a prática de ensino no contexto de um curso básico de língua inglesa?; (b) qual a concepção do professor ou da professora sobre o trabalho que é desenvolvido na sala de aula de língua estrangeira?; (c) como a língua estrangeira se situa em outros contextos, fora da sala de aula da escola de inglês?

Apresentamos, na próxima seção, o referencial teórico que norteia o nosso estudo.

\section{DISCURSO COMO PRÁTICA SOCIAL E DIALOGISMO}

No presente trabalho, compartilhamos da visão de Fairclough (2003) para quem os discursos são "formas de representação de aspectos do mundo - os processos, relações e estruturas do mundo material, do 'mundo mental' dos pensamentos, dos sentimentos, das crenças e assim por diante, e do mundo social"1. Sendo socialmente situado e constrangido nos contextos em que se realiza, o discurso pode ser compreendido como uma das dimensões das práticas sociais. As práticas que, como Street (2012) destaca, são modos de pensar e de agir socioculturalmente orientados que se tornam observáveis em eventos comunicativos com propósitos específicos, podem, na concepção de Fairclough (2003, p. 25), ser entendidas como "articulações de diferentes tipos de elementos sociais que estão associadas a áreas particulares da vida em sociedade" ${ }^{2}$. Portanto, as práticas compreendem as ações e as interações realizadas entre as pessoas nas suas relações sociais, nas quais os discursos representam diferentes formas de ver o mundo.

Isso significa que o discurso é de natureza essencialmente responsiva, "produto da interação de dois indivíduos socialmente organizados" (BAKHTIN, 2006, p. 114), o que pressupõe que, por ser socialmente situada, essa interação é limitada pelas coerções que se impõem sobre o que se diz. Essas coerções definem, conforme as práticas sociais nas quais os indivíduos se movimentam, o que pode ser dito, estabelecendo paradigmas socialmente aceitos que orientam a prática discursiva na sociedade, como "um conjunto

\footnotetext{
1 Tradução nossa do original: "I see discourses as ways of representing aspects of the world - the processes, relations and structures of the material world, the 'mental world' of thoughts, feelings, beliefs and so forth, and the social world" (FAIRCLOUGH, 2003, p. 124).

2 Tradução nossa do original: "Social practices can be seen as articulations of different types of social element which are associated with particular areas of social life - the social practice of classroom teaching in contemporary British education, for example" (FAIRCLOUGH, 2003, p. 25).
} 
de regras anônimas, históricas, sempre determinadas no tempo e no espaço" (FOUCAULT, 2008, p. 133). Há, nesse sentido, conforme Foucault, uma ideia de disciplina, que deve ser obedecida e que rege os ditos em sociedade, moldando os discursos em consonância com valores socialmente instituídos, segundo a qual "não nos encontramos no verdadeiro senão obedecendo às regras de uma 'polícia' discursiva que devemos reativar em cada um de nossos discursos." (FOUCAULT, 1996, p. 35). Segundo Foucault, essa disciplina "é um princípio de controle da produção do discurso. Ela lhe fixa os limites pelo jogo de uma identidade que tem a forma de uma reatualização permanente das regras." (1996, p. 36).

Dessa forma, a concepção do discurso está inevitavelmente associada à prática social, uma vez que, qualquer que seja a sua realização, o discurso encontra nas diversas esferas de relações em sociedade o seu legítimo espaço de atualização, situando-se em diversas estruturas, sejam elas políticas, econômicas, governamentais, da sociedade civil, entre outras. Nesse sentido, Fairclough (2010, p. 59) propõe que "o discurso é modelado pelas estruturas, mas também contribui para modelar, remodelar, reproduzir e transformar essas estruturas", , o que propicia a compreensão do discurso na dimensão das mudanças sociais que podem ser efetivadas.

Para Maingueneau (2008, p. 20), o discurso pode ser compreendido a partir da oposição de "um sistema de restrições de boa formação semântica (a formação discursiva) ao conjunto de enunciados produzidos de acordo com esse sistema (a superfície discursiva)". A articulação desses dois conceitos constitui os atos linguísticos que se realizam em discursos socialmente situados, sistemas de enunciações específicas aplicados a contextos sociais definidos.

Destacamos, contudo, que o discurso não deve ser conceituado somente nos limites dos sistemas de regras e dos constrangimentos socialmente impostos que definem as suas formas. Apesar das coerções às quais são submetidos, os discursos adequam-se às diferentes relações e percepções sociais, elaborando representações do mundo em que vivemos que podem transformar as maneiras como vemos, nos posicionamos e interagimos em sociedade. Segundo Fairclough (2003, p. 124):

\begin{abstract}
Diferentes discursos são diferentes perspectivas do mundo, e estão associados às diferentes relações que as pessoas têm com o mundo, que, por sua vez, dependem das suas posições no mundo, das suas identidades pessoais e sociais, e das relações sociais que têm com outras pessoas. Os discursos não somente representam o mundo como ele é (ou como é visto), mas também são projetivos, imaginários, representando possíveis mundos, diferentes do mundo real, e relacionados a projetos para mudar o mundo em sentidos específicos ${ }^{4}$.
\end{abstract}

\footnotetext{
${ }^{3}$ Tradução nossa do original: “...discourse is shaped by structures, but also contributes to shaping and reshaping them, to reproducing and transforming them” (FAIRCLOUGH, 2010, p. 59).

${ }^{4}$ Tradução nossa do original: "Different discourses are different perspectives on the world, and they are associated with the different relations people have to the world, which in turn depends on their positions in the world, their social and personal identities, and the social relationships in which they stand to other people. Discourses not only represent the world as it is (or rather is seen to be), they are also projective, imaginaries, representing possible worlds which are different from the actual world, and tied in to projects to change the world in particular directions" (FAIRCLOUGH, 2003, p. 124).
} 
É a noção de discurso como prática social que orienta a nossa reflexão no presente artigo e que norteia as nossas considerações sobre as relações interdiscursivas no contexto da sala de língua estrangeira, complementada pelo conceito de interincompreensão regulada, do qual tratamos brevemente a seguir.

\section{A INTERINCOMPREENSÃO REGULADA}

No âmbito das relações sociais dialógicas nas quais são definidos os contextos para os discursos, ocorrem trocas por meio das quais é possível atribuir sentidos aos atos comunicativos. Essas trocas propiciam o ambiente para a análise de discurso, para a compreensão dos fenômenos envolvidos nas relações interdiscursivas. É nesse cenário que se trata do conceito de interincompreensão regulada. Por interincompreensão regulada, Maingueneau (2008) considera que nos processos de interação discursiva em sociedade são feitas traduções dos ditos, no sentido de que interpretamos o outro com base em nossa própria perspectiva do discurso alheio. Conforme Maingueneau (2008, p. 21), "cada um introduz o Outro em seu fechamento, traduzindo seus enunciados nas categorias do Mesmo e, assim, sua relação com esse Outro se dá sempre sob a forma do "simulacro" que dele constrói”. Ou seja, não há um discurso propriamente dito, mas traduções de discurso e imagens que construímos do outro à luz das interações que se desenvolvem em sociedade. Na relação interdiscursiva há, portanto, como Maingueneau define, um tradutor ou tradutora (discurso-agente) e um traduzido ou traduzida (discurso-paciente), sendo "em proveito do primeiro que se exerce a atividade de tradução" (2008, p. 100).

Podemos entender essa tradução como uma leitura do discurso do outro, orientada pelos valores do tradutor ou tradutora que, por sua vez, são socialmente constituídos no contexto do qual o discurso-agente participa. Maingueneau destaca, ainda, que o sentido do discurso, contido em semas positivos (reivindicados) e negativos (rejeitados), quando traduzido, é enfocado na perspectiva do "registro negativo de seu próprio sistema" (p. 100), o que sugere que a compreensão do discurso é regulada no sentido da incompreensão que se estabelece entre os atores sociais nas trocas interdiscursivas.

Esse conceito é relevante para a análise das interações discursivas que se realizam na sala de aula de língua estrangeira, no sentido de que pode contribuir para o conhecimento dos problemas de natureza dialógica naquele contexto. Tratamos desse ponto a seguir.

\section{A NATUREZA DIALÓGICA DA COMUNICAÇÃO}

A perspectiva bakhtiniana considera a natureza essencialmente dialógica das relações sociais, com base no argumento de que "a vida é dialógica por natureza. Viver significa participar do diálogo: interrogar, ouvir, responder, concordar, etc." (BAKHTIN, 2011, p. 348).

É preciso considerar, contudo, que há fatores sociais que constrangem a natureza dialógica da comunicação, impondo limites às relações e definindo os papéis que são 
desempenhados dentro de um contexto social estabelecido. Em função do estabelecimento dos papéis nas relações sociais, ocorre uma atribuição de competências que moldam os modelos de comportamentos, valores e atitudes socialmente aceitos e reforçados em relações assimétricas de poder. Um dos contextos sociais nos quais essa assimetria de poder destaca-se é a sala de aula de língua estrangeira.

Nesse sentido, Blommaert (2005) aponta três problemas que limitam o escopo do dialogismo em sociedade. No que concerne ao contexto social da sala de aula de língua estrangeira, podemos situar os problemas destacados por Blommaert nas seguintes perspectivas.

a) O diálogo não pressupõe cooperação

O grupo de pessoas reunidas na sala de aula de língua estrangeira, participando com frequência do mesmo ambiente e nele desempenhando tarefas com objetivos que, supostamente, são convergentes em seus fundamentos básicos, poderia, em tese, significar que a cooperação é um elemento garantido entre os participantes que compõem o contexto escolar. Contudo, ao que nos parece, com base nas observações realizadas na sala de aula de uma escola de língua inglesa, o diálogo promovido entre os participantes no contexto escolar mostra-se, muitas vezes, forjado por convenções formais que são institucionalmente motivadas e funcionalmente orientadas, tendo em vista o desenvolvimento de habilidades específicas e a obtenção de resultados. Cooperase na medida em que essa cooperação conduz a chances de sucesso e promoção na escola. Assim, o que se observa é o enfoque nos interesses e projetos dos atores sociais, o que gera um certo isolamento das pessoas que poderiam compartilhar do espaço social da sala de aula. Tendo isso em vista, passamos à segunda questão relacionada aos limites de compartilhamento impostos na relação dialógica na sala de aula de língua estrangeira.

b) O diálogo não pressupõe compartilhamento

No contexto escolar, é comum observar situações em que cada pessoa age como um indivíduo que está fisicamente próximo dos demais participantes naquele contexto, mas ao mesmo tempo socialmente desconectado do grupo. Dessa forma, parece haver um distanciamento social entre os membros do grupo que pode ser constatado em algumas situações que observamos na sala de aula de língua estrangeira, por exemplo: em diversas ocasiões, os alunos e as alunas não sabem - ou não lembram - os nomes de muitos dos seus colegas de classe, o que torna a relação entre eles distante e impessoal. Acreditamos que isso pode ocorrer em consequência de uma possível dissociação entre os contextos escolar e social. Nessa perspectiva, a escola de língua estrangeira tem um espaço bem definido nas vidas das pessoas, estando distanciada, na sua esfera, dos demais fazeres sociais que se realizam fora da sala de aula. Assim, estar na escola às vezes nem parece gerar o mesmo sentimento cívico de estar em sociedade, transmitindo a ideia de que as pessoas aparentemente se transportam para um outro mundo ao passar pela porta da sala de aula, o que lhes pode fazer sentir como se realmente não fizessem parte daquele lugar, verdadeiros estrangeiros em um território que não lhes pertence. $\mathrm{Na}$ concepção de Kristeva (1991), o estrangeiro é "aquele que não pertence ao grupo, que 
não é 'um deles', o outro"5 (p. 95). O estrangeiro é identificado pelas diferenças individuais e sociais que podem motivar a sua segregação do grupo, gerando o não compartilhamento de valores e atitudes naquele grupo. Ser estrangeiro é reconhecer-se diferente do outro, é estranhar-se a si mesmo ou a si mesma pelo que não encontramos no outro, rejeitando o que não pode ser compreendido no âmbito dos nossos valores constituídos e que pode apresentar-se como alguma forma de desafio ou ameaça. Nesse entendimento, podemos sempre nos ver e posicionar como estrangeiros, nos contextos socioculturais nos quais nos situamos, pois "o estrangeiro surge quando a consciência da minha diferença se manifesta e desaparece quando nos reconhecemos todos estrangeiros, avessos aos vínculos e às comunidades" (KRISTEVA, 1991, p.1). Considerando que o diálogo não implica cooperação nem compartilhamento entre os participantes envolvidos nas interações, é relevante ponderar sobre as posições assumidas pelo diálogo na sala de aula, no que concerne às relações de autoridade e poder. A questão do diálogo e da simetria do poder, da qual tratamos a seguir, é o terceiro problema da natureza dialógica da comunicação.

\section{c) O diálogo não pressupõe simetria na contextualização do poder}

$\mathrm{Na}$ sala de aula de língua estrangeira, é comumente observável a postura do professor ou da professora como fonte primordial do conhecimento linguístico. Ao (À) aprendiz, é normalmente atribuído o papel de receptor(a) dos conhecimentos ministrados pelo professor ou professora, dentro de uma estrutura organizacional na qual o conhecimento transmitido é graduado e periodicamente testado. Dessa forma, configura-se a relação dialógica na escola na qual se estabelecem as metas e os limites no processo de aprendizagem da língua estrangeira. Nesse contexto, a relação dialógica na sala de aula delimita as tarefas do(a) aprendiz e define o poder institucional do professor ou da professora pelo discurso privilegiado deste ou desta que se impõe aos aprendizes, gerando uma relação de controle mutuamente assimilada. Por essa ótica, o diálogo na sala de aula não promove a simetria de poderes e competências, mas, ao contrário, estipula quais as expectativas que se deve ter de cada um(a) daqueles(as) participantes da interação.

Tomando por base a ancoragem teórica apresentada até esse ponto do nosso trabalho, passamos agora à análise do discurso de uma sala de aula de língua inglesa, considerando também registros de eventos nos quais a língua estrangeira se situa fora da sala de aula.

Entendemos que o referencial teórico adotado neste estudo propicia, em suas bases epistemológicas, a compreensão bakhtiniana da natureza dialógica das relações sociais em que se encontra a sala de aula, marcadas pelos limites impostos a esse dialogismo, com base em Blommaert (2005), e pela perspectiva de uma estrutura social na qual se registre a interincompreensão regulada do discurso (MAINGUENEAU, 2008), orientada por sistemas de regras que geram constrangimentos em contextos

\footnotetext{
${ }^{5}$ Tradução nossa do original: "The one who does not belong to the group, who is not 'one of them', the other" (KRISTEVA, 1991, p. 95).

${ }^{6}$ Tradução nossa do original: “...the foreigner comes in when the consciousness of my difference arises, and he disappears when we all acknowledge ourselves as foreigners, unamenable to bonds and communities" (KRISTEVA, 1991, p. 1).
} 
socialmente situados. Percebemos que na sala de aula, onde se encontra uma relação assimétrica de poder entre professor ou professora e alunos e alunas, as noções de controle discursivo e de conjunto de regras defendidas por Foucault $(1996,2008)$ podem configurar-se como parte das interações realizadas entre os atores sociais. Contudo, no presente estudo, buscamos também a compreensão do discurso em uma perspectiva de mudança social, com base em Fairclough (2003), na qual é possível encontrar possibilidades de transformação nos contextos em que as relações sociais são operadas, concebendo que o discurso, por ser socialmente situado, molda as estruturas sociais e, ao mesmo tempo é moldado por elas, inscrevendo-se em processos de constante ressignificação das percepções que as pessoas têm do mundo ao seu redor.

\section{PROCEDIMENTOS METODOLÓGICOS}

As considerações que apresentamos neste artigo tomam por base os dados coletados e gerados em uma escola de língua inglesa localizada na cidade de Fortaleza, capital do estado do Ceará, durante o segundo semestre letivo de $2012^{7}$. A escola em foco, que aqui chamaremos de ELI - Escola Local de Inglês -, oferece o curso básico de língua estrangeira organizado em sete semestres letivos, com a carga de 60 horas/aula em cada semestre. A escolha dessa escola como contexto da nossa investigação foi motivada pelo fato de tratar-se de uma escola de referência no ensino da língua inglesa na cidade, uma vez que a ELI faz parte de um projeto de extensão de uma universidade pública local e no seu quadro docente há somente professores e professoras formados em Letras atuando em sala de aula, dos quais a maioria atualmente é pós-graduada. Além disso, o fato de que trabalhamos na referida escola facilitou o acesso para a realização do nosso estudo naquele contexto. Os dados foram coletados/gerados em uma turma de Inglês I, nível iniciante do curso, cujas aulas aconteciam duas vezes por semana com duração de uma hora e quarenta minutos em cada dia. Na turma em que as aulas foram observadas, havia 22 alunos matriculados, entre homens e mulheres, de diferentes faixas etárias e de diversos níveis de escolaridade, havendo na turma alunos e alunas de Ensino Médio, de cursos de Graduação e de Pós-Graduação. A professora da turma é pós-graduada em ensino de línguas.

A coleta/geração dos dados desse estudo foi realizada em três etapas, nas quais foram adotados os seguintes procedimentos. Na primeira etapa da coleta de dados, foram acompanhados três dias de aulas na turma em observação. Em geral, como mencionamos anteriormente, há duas aulas por semana nas turmas da ELI; todavia, na semana em que realizamos a coleta, a professora havia planejado ministrar três dias de aulas, para compensar uma falta, e decidimos - com o consentimento da professora estender nossa observação na sua sala de aula, com o objetivo de compreender a perspectiva que orienta o ensino da língua naquele contexto específico. Durante esse acompanhamento de aulas, foram feitas notas de campo nos três dias em que estivemos

\footnotetext{
${ }^{7}$ Os dados aqui apresentados foram coletados e gerados entre os meses de outubro e dezembro de 2012 e fazem parte de uma pesquisa em andamento. Para a realização da pesquisa, foi firmado um termo de consentimento, dando ciência dos procedimentos adotados e autorizando sua divulgação.
} 
presentes na turma. No segundo momento, realizamos uma entrevista semiestruturada com a professora da turma de Inglês I. O objetivo dessa entrevista foi conhecer a sua concepção sobre o trabalho desenvolvido no ensino da língua estrangeira. Para a preparação dessa entrevista, seguimos as orientações propostas por Magalhães (2006), pondo em foco a fala da professora por meio de perguntas que propiciassem à entrevistada o "direito a manifestar-se livremente sem imposições de quem entrevista" (p. 86). No terceiro momento, adotamos diários de participantes e contamos com a participação de oito dos matriculados na disciplina de Inglês I. O objetivo desses diários foi registrar, no período de uma semana, os contatos que os alunos e alunas da turma tinham com a língua inglesa em outros contextos, fora da sala de aula da ELI, para gerar conhecimento sobre algumas das práticas socialmente situadas nas quais o uso da língua se manifesta. Para a elaboração do diário de participante, adotamos o modelo de procedimento de Jones, Martin-Jones e Bhatt (2012), tendo em vista a documentação de "eventos reais nas rotinas diárias atuais de participantes" (p. 117), fazendo uso de um instrumento que viabilizasse o registro de situações nas quais o uso socialmente situado da língua inglesa pode ser observado.

A seguir, apresentamos a análise dos dados, tendo em vista a reflexão sobre a prática discursiva na sala de aula e fora dela, bem como sobre os limites observados nas relações dialógicas que se desenvolvem nesses contextos.

\section{ANÁLISE DOS DADOS}

Para realizar a análise, enfocamos a natureza socialmente situada do discurso na tessitura das nossas considerações sobre os dados registrados em cada etapa do estudo. Para o tratamento dos dados coletados/gerados, propomos uma análise de aspectos textuais, combinada à análise de aspectos relacionados às práticas discursivas registradas.

Para a análise textual, adotamos as categorias propostas por Fairclough (2001, p. 103), no seu quadro analítico geral, abordando os seguintes itens: gramática, vocabulário, coesão e estrutura textual. Conforme Fairclough, a gramática trata das combinações de palavras em orações e frases, abordando as escolhas feitas pelas pessoas quanto ao modelo e à estrutura de suas orações. $\mathrm{O}$ vocabulário enfoca o uso de palavras individuais, levando em consideração as significações conforme as escolhas do léxico, os sentidos expressos, a utilização de palavras (nos termos de Fairclough, 'wording'), bem como o uso de metáforas. Na coesão, considera-se a ligação entre orações e frases na formação da unidade textual, merecendo destaque, como recursos coesivos, o uso de palavras repetidas, sinônimos, substituições por referência (pronomes, artigos definidos, demonstrativos, entre outros), bem como o uso de conjunções ('portanto', 'contudo', 'entretanto', 'mas', 'nem', 'e', 'ou', 'pois', etc.). A estrutura textual envolve os aspectos organizacionais do texto em uma dimensão mais ampla, considerando a forma como o texto é arquitetado para construir o significado que se pretende expressar. 
Articulada à análise textual, também realizamos a análise sociodiscursiva da relação dialógica nos discursos sobre o ensino e o uso da língua estrangeira. Nesse ponto, trazemos ao debate as considerações de Blommaert (2005), acima discutidas (veja Seção 4), relativas às limitações da natureza dialógica da comunicação, enfocando: a cooperação, o compartilhamento, e a simetria de poder nas relações dialógicas.

Dessa forma, organizamos a análise dos dados em três seções, referentes às etapas seguidas na pesquisa: (1) a observação na sala de aula; (2) a entrevista com a professora; (3) os diários de participantes (alunos e alunas).

\subsection{A OBSERVAÇÃO NA SALA DE AULA}

Na primeira etapa de coleta de dados, durante o acompanhamento de uma semana de aulas em uma turma de Inglês I - nível iniciante do curso básico de língua inglesa -, observamos que as aulas ministradas foram organizadas dentro de um padrão estritamente estruturado e controlado pela professora. Nesse sentido, o próprio espaço físico da sala de aula, caracterizado pelo uso de artefatos (como tiras de papel em tamanho ampliado, afixadas nas paredes, mostrando frases feitas para a comunicação em inglês na sala de aula), bem como a forma da disposição de informações no quadro branco - que foi organizado em colunas para expor a data, a sequência da aula no calendário letivo, as tarefas do dia e da aula seguinte, bem como anotações distintas sobre itens de gramática, vocabulário e pronúncia -, refletiu o compromisso da professora com o gerenciamento das atividades realizadas em sala de aula. Em outras palavras, tudo parecia estar sob o controle da professora que, algumas vezes, se posicionava de maneira muito autoritária, diante dos alunos e das alunas. Aos alunos e alunas foi atribuído o papel de participantes passivos na sala de aula, em uma posição secundária, na qual as suas reações eram desencadeadas pelos comandos e estímulos produzidos pela professora. Nesse contexto, foram desenvolvidas as relações dialógicas em sala de aula, tendo por objetivo a prática discursiva na língua estrangeira, conforme os procedimentos didáticos predeterminados pela professora em consonância com o programa do curso ministrado.

Nos seguintes extratos, registrados durantes as aulas observadas, podemos exemplificar a prática discursiva desenvolvida em diferentes momentos das aulas, no contexto acima descrito. $\mathrm{Na}$ transcrição das falas, nos registros feitos pelos participantes, as pausas são representadas por três pontos. As interrupções no fluxo de fala são representadas por três pontos entre parênteses. Os colchetes registram comentários ou observações do pesquisador.

P: Se vocês não participarem, eu não poderei ajudá-los a se preparar para as provas. Aí, no dia da prova, já vai ser tarde demais.

P: I read a newspaper every day.

[alunos e alunas repetem em coro]

P: What's the negative?

Al: I don't read a newspaper every day. 
[alunos e alunas respondem em coro]

(3) P: Vocês não sabem perguntar ainda não! Só na próxima unidade... Faz de conta que não sabe!

(4) P: Quando eu comecei a ensinar, a gente usava exercícios de repetição e os alunos não trocavam as formas verbais. A gente não chegava no semestre 4 dizendo 'he don't'.

No que concerne aos elementos textuais, percebemos que, no aspecto da gramática, a fala da professora, em (1), é marcada pelas orações com estrutura declarativa e pela modalidade objetiva. Conforme Fairclough (2001), a modalidade objetiva não deixa claro se a posição expressa é a do falante ou de outra pessoa, fato pelo qual a fala da professora parece eximi-la de qualquer ônus, em função da não participação durante as suas aulas. Nesse mesmo extrato, observamos que as escolhas lexicais da professora ("participar", “ajudar", "preparar", "provas”) elaboram um percurso discursivo no qual se faz um alerta aos alunos e alunas. Nesse sentido, a advertência é comunicada por meio dos elos coesivos que são estabelecidos ("Se vocês não...", “eu não...", "Aí, já vai ser...”), estabelecendo uma relação de causa e consequência, na qual se pode imputar aos alunos e alunas o sentimento de responsabilidade pelo eventual insucesso nas avaliações escolares ("tarde demais"). Nessa estrutura textual, é determinada uma agenda dentro da qual as ações devem ser conduzidas: a professora ensina e os alunos e alunas participam para que possam ser preparados para ter sucesso nas avaliações formais. Assim, os elementos textuais sugerem a relação de poder na sala de aula e o diálogo é construído em torno do poder institucional que é exercido pela professora.

Contudo, apesar do apelo da professora (1), não observamos nenhum incremento na cooperação dos alunos e alunas na sala de aula. Os que estavam participando continuaram e os que não participavam permaneceram retraídos. Nesse sentido, constatamos as limitações da relação dialógica, conforme Blommaert (2005), segundo o qual não se pode pressupor cooperação, compartilhamento ou simetria nas relações de poder na produção de um ato comunicativo. $\mathrm{Na}$ tentativa de, possivelmente, sensibilizar os alunos e alunas para a importância da sua participação nas aulas, a professora aparentemente não conseguiu motivá-los, nem mesmo com a força desafiadora da sua enunciação com enfoque na preparação para as avaliações.

$\mathrm{Na}$ maioria das ocasiões em que houve participação dos alunos e alunas durante as aulas observadas, isso aconteceu de forma mecânica, em exercícios de repetição condicionada, como registramos no extrato (2). Nesse segundo extrato, também podemos observar que o diálogo não pressupõe compartilhamento de interesses entre as pessoas envolvidas na prática discursiva. Em (2), observamos que os atos de fala não tencionam expressar um significado socialmente situado nas vidas dos alunos e alunas, mas promover a prática de estruturas linguísticas a esmo, sem importar se, de fato, todos leem jornais ou não. Uma vez esvaziado de significado, cria-se nesse discurso um novo ethos na enunciação que orienta comportamentos e respostas condicionadas. Sendo assim, não há compartilhamento - nem cooperação - porque não há ambiente para isso, já que os alunos e alunas não sabem qual ethos lhes será atribuído naquela sala de aula. Compreendendo o ethos como "o comportamento total de um(a) participante" (FAIRCLOUGH, 2001, p. 181), do qual fazem parte não apenas as expressões verbais, 
mas as posturas que são manifestadas em uma determinada situação de interação, percebemos que as relações dialógicas desenvolvidas na sala de aula sugerem o diálogo em conformidade com as regras e metas traçadas pela professora. Nessa relação interdiscursiva, os alunos e alunas simplesmente reagem às situações impostas durante a aula e, portanto, não podem sentir-se socialmente responsáveis pelos textos das suas vidas naquele contexto. Conforme as situações previstas e estruturadas na sala de aula, desenvolve-se uma dialogicidade inter-regulada na qual são fornecidas respostas aos estímulos, conforme os objetivos do plano de ensino do dia, controlando o que deve ou não ser dito, o discurso. Nesse sentido, os participantes passivos - discurso-pacientes, na concepção de Maingueneau (2008) - tentam cumprir as metas definidas pela participante ativa - discurso-agente, nos termos de Maingueneau (2008) - em uma relação dialógica motivada pela expectativa da recompensa, que consiste na obtenção dos conhecimentos linguísticos e na subsequente aprovação pela professora. Essa dialogicidade inter-regulada é organizada conforme os moldes estabelecidos para a relação interdiscursiva, e fora desse padrão o discurso tende a ser rejeitado ou considerado inadequado, diante dos objetivos traçados para a prática discursiva na sala de aula.

Em (3), observamos uma outra amostra de dialogicidade inter-regulada. Esse extrato foi registrado durante um momento de uma das aulas observadas, quando os alunos e alunas estavam envolvidos com a prática do presente simples de verbos para falar sobre hábitos na primeira pessoa do singular, que era o foco da atividade proposta pela professora. Durante a realização do exercício, embora não tivessem sido instruídos pela professora para fazê-lo, alguns alunos e alunas começaram a formular perguntas aos seus pares, como forma de dar um encadeamento lógico ao diálogo, o que provocou a reação da professora, que transcrevemos no extrato (3).

Nesse extrato, percebemos novamente a marca da autoridade da professora, que se deixou registrar nos seus aspectos textuais. No aspecto gramatical, a escolha de uma oração negativa ("Vocês não sabem...") e da modalidade objetiva, que, conforme Fairclough, "implica alguma forma de poder" (2001, p. 200), contribui para definir os limites da prática discursiva, controlando os atos de fala, em respeito aos objetivos do plano da aula. As escolhas lexicais da professora também sinalizam nesse sentido ("não", "perguntar", "próxima unidade", "Faz de conta...”) e, aliadas aos elos coesivos utilizados ("ainda não", "Só na próxima..."), expressam a sua preocupação com o desenvolvimento da aula, em conformidade com o que havia sido planejado. Ao que nos parece, pela estrutura textual construída na fala da professora, houve uma tentativa de estabelecer uma agenda em que houvesse um instante idealizado, no qual a prática discursiva pudesse ser encapsulada, minimizando os riscos de erros, para que fosse possível passar para a "próxima unidade" do programa com domínio linguístico daquele conteúdo.

No aspecto discursivo, fica evidente em (3) que o diálogo não pressupõe simetria nas relações de poder (BLOMMAERT, 2005). A professora disse aos alunos e alunas o que eles sabiam fazer, estipulando o alcance das suas competências. As outras competências deveriam ser deixadas para depois, pois seriam adquiridas na unidade seguinte do programa do curso. Uma vez estabelecidas as metas, o exercício continuou 
a ser realizado, embora houvesse ainda a resistência de alguns alunos e alunas a dialogar sem fazer perguntas. Esse fato, percebido pela professora ao se aproximar dos grupos que conversavam em inglês, forçou-a a expor brevemente a estrutura da forma interrogativa dos verbos no presente simples. Contudo, a professora apresentou somente as formas para o diálogo nas perspectivas da primeira e da segunda pessoa do singular e pediu que a terceira pessoa do singular não fosse utilizada, já que essa estrutura seria estudada mais adiante no programa. Percebemos, mais uma vez, que o poder institucional da professora foi muito marcante nesse momento da interação na sala de aula. O diálogo forjado em torno de situações cotidianas não implicou simetria de poder no contexto da sala de aula e os alunos e alunas, desempoderados, acabaram fazendo o que a professora ordenou, sendo que ao final da atividade não lhes foi dada oportunidade de gerar uma resposta para o grupo, para compartilhar suas vivências na língua estrangeira. Passados alguns minutos, a professora simplesmente encerrou a atividade e engatou uma outra para dar sequência à aula.

$\mathrm{Na}$ sequência das atividades em uma das aulas, registramos um momento no qual a professora fala aos alunos e alunas da turma sobre a importância dos exercícios de repetição de padrões linguísticos feitos na sala de aula, como no extrato (2). Nesse sentido, percebemos em (4) que a professora resgata, pela referência ao passado ("Quando eu comecei a ensinar..."), uma memória de como os alunos eram ensinados no passado. O argumento é ratificado por meio das escolhas lexicais feitas e das relações coesivas ("a gente usava...", "e os alunos não trocavam...") que implicam uma defesa da eficácia de uma técnica de ensino que é adotada pela professora na sua prática discursiva em sala de aula. Aqui, a noção de progresso, representada pelo alcance de graus mais elevados no estudo da língua estrangeira ("semestre 4"), e expressa pelo verbo 'chegar', é atestada pela habilidade de dominar as estruturas formais da língua estrangeira, conforme a professora ("A gente não chegava no semestre 4 dizendo he don't”). Portanto, o controle interacional, enfocado na estrutura textual da fala da professora, é justificado pelo domínio linguístico supostamente obtido em função dos exercícios de repetição, o que tende a legitimar essa perspectiva de ensino da língua.

Em termos de prática discursiva, na relação dialógica na sala de aula, a relação assimétrica de poder faz-se presente, influenciando a forma como os alunos e alunas percebem os seus papéis na sala de aula. Como não há simetria na contextualização do poder, cabe aos alunos e alunas seguir as orientações e preceitos da professora, se realmente quiserem 'aprender' a língua estrangeira. Percebemos, portanto, que a prática de ensino da língua inglesa, no contexto em foco, é orientada em uma perspectiva de desenvolvimento mecânico de habilidades linguísticas, condicionada à exposição e repetição controlada com enfoque nos aspectos formais da língua. Essa perspectiva é confirmada na segunda etapa da investigação, quando realizamos a entrevista semiestruturada com a professora da turma de Inglês I. Tratamos dos aspectos relativos a essa entrevista na próxima seção. 
A entrevista semiestruturada foi realizada antes do início de uma das aulas observadas, na sala dos professores da ELI, com o objetivo de conhecer a concepção da professora sobre o trabalho desenvolvido na sala de aula de língua estrangeira. Os dados gerados na entrevista sugerem perspectivas sobre a prática docente, os papéis assumidos e atribuídos no contexto formativo, bem como sobre a relação entre escola e sociedade. Essas concepções podem fomentar debates e questionamentos que visam contribuir para a compreensão da relevância do ensino socialmente situado da língua estrangeira.

Os seguintes extratos da entrevista exemplificam as concepções reveladas pela professora sobre as questões referentes ao ensino da língua estrangeira. Com base nestes extratos, tencionamos tecer as nossas considerações sobre a fala da professora.

$\mathrm{P}$.... a gente tem que trabalhar sempre dentro de um modo muito estruturado pra poder a gente fazer o que... uma avaliação... (...) eu acho que acaba sendo bastante artificial porque o que a gente traz pra sala de aula nem sempre é aquilo que o aluno precisa pra sua realidade.

P:... eles [os alunos e alunas], na verdade, vêm pro curso pra adquirir a parte formal, estruturada da língua. Porque essa outra parte, essa parte informal do uso cotidiano, eu não vejo que ela seja aprendida conosco. Porque a gente não dá muita ênfase nisso. Talvez nem precise...

P: Ele deveria ser aquele ser que vem pra sala de aula pra sugar do professor tudo que aquele professor tem pra oferecer em termos de conhecimento adquirido, em termos de cultura, em termos de norma culta. (...) Ele deveria ser extremamente participante...

Em uma análise dos aspectos textuais, percebemos que no extrato (1) a oração declarativa ("a gente tem que...") exprime a ideia da missão a ser cumprida, no sentido do que se espera do professor ou da professora de língua estrangeira. Essa missão culmina quando o trabalho feito na sala de aula é posto à prova, o que fica expresso na escolha lexical que representa um momento considerado, aparentemente, fundamental ("avaliação"). Observamos, também, no que concerne ao caráter socialmente situado do ensino da língua estrangeira, que a adoção de uma modalidade subjetiva ("eu acho que...”), combinada a um marcador de indeterminação ("bastante”), parece sugerir uma crítica à superficialidade do trabalho desenvolvido na sala de aula. Pela modalidade subjetiva, a professora assume uma baixa afinidade com a enunciação e, conforme Fairclough (2001), a baixa afinidade pode significar "falta de poder, e não falta de convicção ou conhecimento" (p. 201) para se posicionar com relação a um tema. A relação de coesão estabelecida pela conjunção ("porque") introduz o motivo dessa alegada superficialidade ("o que a gente traz pra sala de aula nem sempre é aquilo que o aluno precisa..."). Contudo, na estrutura textual da fala da professora, identificamos uma agenda na qual é patente uma conformação com o estado de coisas que é constatado, sem esboçar uma posição crítica, denotando que parece haver um afastamento da complexa questão evocada, relativa ao entrelaçamento entre a prática escolar e as demais práticas sociais.

Essa postura de conformação com o trabalho socialmente superficial que é feito na sala de aula é confirmada em outras passagens da entrevista, como no extrato (2). 
Nesse segundo extrato, observamos que o contraste entre as escolhas lexicais feitas ("formal", "informal"), para se referir aos contextos nos quais a língua pode ser usada, identifica uma visão dicotômica que tende a segregar a escola da sociedade, como se os fazeres escolares pudessem ser distintos dos demais fazeres socialmente situados. $\mathrm{O}$ distanciamento entre as práticas escolares e as práticas sociais situadas nas vidas extraescolares das pessoas parece estar determinado na estrutura textual da fala da professora. Observamos que o emprego de pronomes (“...essa outra parte, essa parte informal...") sugere o distanciamento entre escola e sociedade, no sentido de isentar a escola da responsabilidade de incluir-se em contextos socialmente situados do uso da língua (“...eu não vejo que ela seja aprendida conosco...”). Nesse extrato da entrevista, a modalização ("Talvez nem precise...") marca a subjetividade e indeterminação na posição assumida pela professora, possivelmente visando evitar o compromisso com o enunciado sobre a necessidade de assimilar na sala de aula de língua estrangeira os contextos de interação socialmente situados.

Nessa perspectiva, considerando que faz parte da missão do professor ou da professora de língua estrangeira ministrar conteúdos para transmitir aos alunos e alunas conhecimento formal da língua, observamos no extrato (3) que o papel dos aprendizes da língua estrangeira é definido com base na idealização de um preceito-chave: a participação. Em termos de gramática, a modalização expressa na forma verbal ("Ele deveria ser aquele..."), aliada à escolha lexical ("sugar"), parece confirmar, pela metáfora adotada, a percepção do aluno ou aluna como um participante passivo na sala de aula de língua estrangeira. A coesão textual, recorrendo ao destaque da figura da professora pela repetição do substantivo, reforça essa percepção da passividade do aluno ou aluna em contraste com a posição ativa da professora (“...pra sugar do professor tudo que aquele professor tem pra oferecer..."). Nesse sentido, os elementos gramaticais, lexicais e coesivos concorrem para o estabelecimento da estrutura textual no extrato (3) que sugere uma agenda determinada e policiada com base na relação de poder assimétrica entre os atores sociais na sala de aula de língua estrangeira, na qual valores e atitudes são assumidos e as expectativas precisam ser cumpridas ("Ele deveria ser extremamente participante...") para manter o sistema em operação.

Em termos da análise dos aspectos discursivos, observamos, nos três extratos que ilustram a fala da professora sobre o ensino da língua estrangeira, as limitações destacadas por Blommaert (2005) na natureza dialógica da comunicação. A posição assumida pela professora na entrevista sinaliza no sentido de compreender o discurso da sala de aula de língua estrangeira em uma perspectiva de dissociação entre escola e sociedade. Ao reconhecer que o trabalho feito na sala de aula não apresenta conteúdos dos quais os alunos e alunas realmente precisam nas suas vidas sociais, parece haver a aceitação de um trabalho didático que promove a descontinuidade de valores socialmente referenciados, quando se trata de aprender a língua estrangeira. Conforme a professora, uma vez em sala de aula, os alunos devem ser ensinados a manusear as estruturas formais da língua para serem submetidos às avaliações e somente depois, fora da escola, eles poderão usar a língua em contextos reais. Dessa forma, a concepção manifestada pela professora na entrevista sugere a compreensão da sala de aula de língua estrangeira como um espaço desconectado de outros contextos sociais nos quais os alunos e as alunas podem situar-se, e, nessa perspectiva, o trabalho desenvolvido 
nesse espaço tende a ser primordialmente técnico, voltado para o ensino de conceitos formais na língua. Essa configuração da sala de aula promove a concepção de que as relações dialógicas desenvolvidas naquele contexto não implicam cooperação, nem compartilhamento, nem simetria nas relações de poder, conforme discutimos anteriormente (veja Seção 4).

Considerando os dados coletados/gerados na observação de aulas e na entrevista, na sala de aula de língua estrangeira, os alunos e alunas podem posicionar-se como estrangeiros (KRISTEVA, 1991), por não haver uma integração entre as atividades propostas nas aulas e as suas vivências socialmente situadas e, consequentemente, por não ser desenvolvido o sentimento de pertencimento ao contexto. Contudo, observamos que, fora da sala de aula da escola de inglês, há outras práticas discursivas que podem ser realizadas, de forma socialmente significativa, conforme os registros feitos nos diários de participantes, dos quais tratamos a seguir.

\subsection{OS DIÁRIOS DE PARTICIPANTES}

Durante o período de uma semana, enquanto as observações das aulas eram realizadas, oito participantes registraram, por escrito, as situações nas quais a língua inglesa fez parte das suas vidas cotidianas, além dos limites da sala de aula da ELI. Os registros foram feitos pelos próprios participantes, utilizando um diário semiestruturado no qual os alunos e alunas escreveram informações em colunas, referentes às situações nas quais tiveram experiências em que ouviram, falaram, leram, ou escreveram algo na língua inglesa, em cada período do dia - manhã, tarde, ou noite - fora do contexto da sala de aula de língua estrangeira.

Os dados gerados nesses diários confirmam que a língua estrangeira está presente e se atualiza em diversas práticas discursivas no cotidiano dos alunos e alunas da ELI. Como foi registrado pelos participantes, seja por meio da internet, em redes sociais, em blogs, ou ainda pelo rádio, em seriados na televisão ou em jornais e revistas, bem como em vários produtos comercializados, há diversos fazeres socialmente situados que são mediados pela língua estrangeira.

Os seguintes extratos dos diários de participantes ilustram os contatos que os alunos e alunas tiveram com a língua estrangeira fora da sala de aula da ELI. Com base nestes extratos, podemos tecer nossas considerações sobre a relevância que essas experiências têm para o processo de consolidação dos conhecimentos linguísticos de alunos e alunas.

\footnotetext{
Li meus e-mails do dia. Acessei o Google e o Facebook.

Música "Wind of Change" - Scorpions. Em frente a uma parada de ônibus, reproduzida por um rádio de uma loja de eletrodomésticos.

É impressionante a quantidade de produtos cujos nomes são em inglês. Da caneta ao lenço de papel (Kiss), a língua inglesa faz-se presente no cotidiano de inúmeras pessoas que, embora sem grande conhecimento da língua, consomem Coca-Cola, usam By express (da Esplanada) e pagam a passagem do ônibus com "passecard" (escrito da maneira como se fala no dia a dia).

"Counterclockwise", na universidade, numa aula de física.
} 
Em termos de análise textual, podemos considerar que a escolha do léxico para fazer os registros nos diários é representativa da presença e familiaridade da língua inglesa no cotidiano das pessoas. No extrato (1), os termos ("e-mail", "Facebook"), originalmente da língua inglesa, são assimilados ao uso corrente, na linguagem diária, e comumente empregados para a comunicação, sem a utilização de recursos de tradução ("e-mails" poderiam ter sido traduzidos como mensagens eletrônicas, por exemplo) ou qualquer recurso de substituição por outros termos da língua portuguesa. Nesse sentido, a língua inglesa parece estar efetivamente integrada às atividades socialmente situadas nas vidas das pessoas e o emprego da expressão temporal (“do dia”) deixa claro que a vivência nesse contexto marcado pela língua estrangeira faz parte do cotidiano.

De forma similar, no extrato (2), os itens lexicais que compõem a descrição da cena urbana ("parada de ônibus", "loja de eletrodomésticos") indicam a natureza socioculturalmente situada do contato com a língua inglesa, que, pela forma registrada no diário do aluno, parece-nos estar enredada no dia a dia, de modo que não pode passar sem ser percebida.

No extrato (3), o relato mais extenso de um dos participantes, observamos que a modalidade objetiva, por meio do uso da forma declarativa ("É..".) combinada à escolha lexical do adjetivo ("impressionante"), expressa uma posição categórica do aluno, com relação à influência da língua inglesa nas relações comerciais na nossa sociedade. A oração declarativa (“...a língua inglesa faz-se presente...”) reforça a modalidade objetiva que pode denotar o empoderamento do aluno, pela posição como membro da sociedade na qual a língua inglesa figura no contexto do mercado de produtos e serviços. Nesse sentido, percebemos que, ao relatar o seu ponto de vista, o aluno parece expressar-se com propriedade, como se falasse de algo que está integrado às suas experiências socialmente situadas e, por consequência, que lhe pertence. Nesse terceiro extrato, a relação de coesão é estabelecida pelo uso de exemplos de atividades que são realizadas pelas pessoas, estabelecendo alguma associação com a língua inglesa (“...consomem Coca-Cola...", "usam By express...", "pagam a passagem do ônibus com passecard”). Dessa forma, na composição da estrutura textual do uso linguístico do aluno conjugamse os elementos textuais, léxicos e coesivos para construir o sentido de que a língua inglesa está situada em distintas interações sociais. Essa percepção se estende a outros contextos mais formais, como a escola e a universidade, onde a língua inglesa pode fazer-se necessária para a compreensão dos conteúdos em estudo, como podemos ver no relato que ilustramos no extrato (4).

No extrato (4) percebemos, no aspecto textual, que o registro de uma palavra em inglês ("counterclockwise") parece materializar a presença da língua inglesa nas atividades das quais as pessoas participam. Nesse extrato, as formas adverbiais ("na universidade", "numa aula") situam a língua estrangeira em um contexto de engajamento e interação em atividades específicas. Portanto, os registros feitos pelos participantes em seus diários sugerem, em seus aspectos textuais, que as pessoas podem encontrar na língua estrangeira um legítimo veículo para a realização das mais diversas atividades que desempenham na sociedade, seja na leitura de textos acadêmicos, seja no comércio, ou em outros contextos. 
No que concerne à análise dos aspectos discursivos, observamos que, nos diários de participante, os registros dos alunos e alunas sinalizam no sentido de compreender a língua inglesa em uma perspectiva dialógica socialmente situada. Nesse sentido, as limitações nas relações dialógicas, relativas à cooperação, ao compartilhamento e às relações de poder, são impostas pelos constrangimentos de ordem sociocultural e não pelos planos de ensino, como ocorre na sala de aula de língua estrangeira. Isso propicia que, em seus contatos e experiências com a língua estrangeira fora da sala de aula da ELI, as pessoas busquem negociar e construir sentidos conforme os recursos linguísticos dos quais dispõem, para a realização de tarefas socialmente significativas. Um dos contextos nos quais a língua estrangeira pode ser empregada para a negociação de sentidos é o acadêmico. No diário de um dos participantes, observamos o seguinte registro:

(5) Li algumas expressões em inglês no TC de química.

Escrevi alguns termos em inglês estudando biologia, tais como linkage e crossing-over.

Nesse extrato, registra-se que a língua inglesa está situada na realização de tarefas acadêmicas, onde os termos utilizados visam, possivelmente, à contextualização e significação de conceitos na estrutura textual em estudo e à consolidação de conhecimentos na prática discursiva.

Portanto, percebemos que em cada contexto social, fora da sala de aula da escola de inglês, há uma identificação das pessoas com valores linguísticos e culturais, o que define posições assumidas pelos usuários da língua. Na medida em que as pessoas se situam como participantes de práticas discursivas, desenvolvem-se ações de cooperação na interação e de compartilhamento no sentido de propriedade e engajamento que são motivados pelos significados representados na língua. Nessa perspectiva, a língua estrangeira não está encapsulada em regras e preceitos escolares, mas ao alcance das pessoas, ampliando as possibilidades de comunicação na sociedade.

\section{CONSIDERAÇÕES FINAIS}

Com base em nossa análise dos dados, podemos inferir que o discurso da sala de aula de língua estrangeira sinaliza que as interações sociais entre os usuários da língua podem ser orientadas por metas programáticas, conforme os objetivos do plano de ensino delineado para uma determinada unidade. Nesse contexto forjado no interior de um sistema socialmente simulado, os participantes falam de hábitos, de profissões, de preferências pessoais, entre outros assuntos; em outras palavras, interagem. Contudo, essa interação se dá não entre os próprios participantes com as suas identidades, mas entre as projeções de personagens que são criadas para a representação de fazeres calculados, construindo na sala de aula as identidades que devem ser assimiladas por cada participante, no processo de aprendizagem da língua. A ideia que subjaz, portanto, é que a língua deve ser praticada, mesmo que de forma socialmente desconexa. 
O discurso nessa sala de aula da ELI, como é confirmado nas observações realizadas e na entrevista semiestruturada, indica que a relação interdiscursiva é desenvolvida com base em comportamentos policiados (FOUCAULT, 1996) que orientam as práticas discursivas entre os atores sociais ao comando da professora. Considerando que, nas trocas discursivas em sociedade, traduzimos o discurso do outro e elaboramos as nossas percepções com base nas imagens construídas por nós, podemos pensar que, na sala de aula de língua estrangeira, a interação parece se desenvolver com base em representações que são criadas para aquele contexto específico, tendo em vista o gerenciamento das práticas discursivas que se desdobram naquele ambiente.

Todavia, quando se trata das experiências linguísticas além da sala de aula, encontramos uma construção essencialmente social de conhecimentos linguísticos. As vivências socialmente situadas contribuem para constituir e consolidar as orientações linguísticas das pessoas e inspiram a busca de novos conhecimentos na língua estrangeira. Dessa forma, o contato com a língua estrangeira pode ser compreendido como uma consequência inextrincável da participação em práticas sociais diversas. De uma ou de outra forma, os atores sociais podem acumular vivências atravessadas pela língua estrangeira, seja pelo contato com filmes, músicas e produções artísticas diversas, ou pelas experiências que as atuais tecnologias digitais proporcionam, seja pela globalização e expansão de conhecimentos que aproximam as produções científicas, as culturas e os mercados. Entendemos, então, que essa bagagem sociocultural, resultante de ações socialmente situadas, pode ser considerada pela escola no processo de instrução formal na língua estrangeira e quando não o é deixa-se de estabelecer um importante elo entre escola e sociedade.

Nessa perspectiva, defendemos uma aproximação e integração entre a escola e outros contextos socialmente situados no sentido de promover o discurso da sala de aula de língua estrangeira fomentado pelas vivências de alunos e alunas, como forma de conjugar ao conhecimento linguístico a formação do pensamento crítico. Consiste nesse ponto o interesse da investigação que temos desenvolvido em nosso estudo, com foco nas práticas discursivas que se realizam na sala de aula de língua estrangeira e fora dela, tendo em vista compreender possíveis caminhos para promover o diálogo entre escola e sociedade.

Os dados coletados/gerados na pesquisa sugerem que a escola de língua estrangeira é considerada em uma dimensão da qual não participam os contextos socialmente situados das vidas das pessoas. Como a professora afirma em um trecho da entrevista, "essa outra parte, essa parte informal do uso cotidiano, eu não vejo que ela seja aprendida conosco", parece haver uma distinção entre os fazeres escolares e os extraescolares. Por outro lado, fora dos limites impostos na sala de aula, alunos e alunas revelam que percebem o uso da língua estrangeira de forma socialmente contextualizada. Nessa ótica, faz-se necessário enfocar a associação entre a sala de aula e outros contextos sociais para gerar, na escola, conhecimento linguístico mais significativo nas vidas das pessoas. Assim, o professor ou a professora pode propiciar a experiência de aprendizagem da língua estrangeira não na perspectiva de valores socialmente desconexos, mas como um recurso dialógico para viabilizar a inclusão 
social de alunos e alunas de forma socioculturalmente posicionada e a realização de mudanças sociais por meio de práticas discursivas criticamente desenvolvidas.

\section{REFERÊNCIAS}

BAKHTIN, M. M. Marxismo e filosofia da linguagem. Trad. de Michel Lahud e Yara Frateschi Vieira. 12. ed. São Paulo: Hucitec, 2006. p. 68-139.

Estética da criação verbal. Trad. de Paulo Bezerra. 6. ed. São Paulo: Martins Fontes, 2011.

BLOMMAERT, J. Discourse. A critical introduction. Nova York: Cambridge University Press, 2005.

FAIRCLOUGH, N. Discurso e mudança social. Coord. da tradução Izabel Magalhães. Brasília: Editora Universidade de Brasília, 2001.

Analysing discourse: textual analysis for social research. Londres: Routledge, 2003.

Critical discourse analysis: the critical study of language. 2. ed. Harlow: Pearson Education

Limited, 2010.

FOUCAULT, M. A ordem do discurso. Trad. de L. F. A. Sampaio. 3. ed. São Paulo: Edições Loyola, [1971] 1996.

. A arqueologia do saber. Trad. L. F. B. Neves. 7. ed. Rio de Janeiro: Forense Universitária, [1969] 2008.

JONES, K; MARTIN-JONES, M; BHATT, A. A construção de uma abordagem crítica, dialógica para a pesquisa sobre o letramento multilíngue - diários de participantes e entrevistas. In: MAGALHÃES, I. (Org.) Discursos e práticas de letramento: pesquisa etnográfica e formação de professores. Trad. de Izabel Magalhães. Campinas: Mercado de Letras, 2012. p. 111-158.

KRISTEVA, J. Strangers to ourselves. Trad. de Leon Roudiez. Nova York: Columbia University Press, 1991.

MAGALHÃES, I. Discurso, ética e identidades de gênero. In: ; CORACINI, M. J.;

GRIGOletTO, M. (Orgs.) Práticas identitárias: língua e discurso. São Carlos: Claraluz, 2006. p. 71-96. MAINGUENEAU, D. Gênese dos discursos. Trad. de Sírio Possenti. São Paulo: Parábola Editoral, 2008. STREET, B. V. Eventos de letramento e práticas de letramento: teoria e prática nos novos estudos do letramento. In: MAGALHÃES, I. (org.) Discursos e práticas de letramento: pesquisa etnográfica e formação de professores. Trad. de Izabel Magalhães. Campinas: Mercado de Letras, 2012. p. 69-92.

\section{Recebido em: 19/09/14. Aprovado em: 07/01/15.}

Title: Foreign language classroom speech: inter-regulated dialogue

Authors: Jader Martins Rodrigues Junior; Izabel Magalhães

Abstract: The present work aims at analysing the discourse of a beginner's foreign language classroom. To do so, we present a brief review of the concept of discourse (FOUCAULT, 1996, 2008; FAIRCLOUGH, 2003, 2010; MAINGUENEAU, 2008), bringing to our discussion the Bakhtinian (2011) principle of dialogism, and the concept of regulated inter-incomprehension (MAINGUENEAU, 2008). For the analysis, our methodology is based on the social theory of discourse (FAIRCLOUGH, 2001), as well as Blommaert's (2005) considerations on the dialogic nature of meaning. Thus, we propose to set the theoretical and methodological basis guiding our analysis of samples of communicative events. As a result of the analysis, we conclude that the interdiscursive relations which take place in this classroom are regulated in interaction, according to the goals set in the course program, generating an inter-regulated dialogue in accordance with the teaching plan.

Key words: Discourse. Dialogism. Classroom. Foreign language.

RODRIGUES JUNIOR, Jader Martins; MAGALHÃES, Izabel. Discurso da sala de aula de língua estrangeira: dialogicidade inter-regulada. Linguagem em (Dis)curso - LemD, Tubarão, SC, v. 15, n. 1, p. 149-168, jan./abr. 2015. 
Título: Discurso de la sala de aula de lengua extranjera: dialogicidad inter-regulada Autores: Jader Martins Rodrigues Junior; Izabel Magalhães

Resumen: Este trabajo tiene como objetivo analizar el discurso en una sala de aula de nivel iniciante, en escuela de lengua extranjera. Así, presentamos una breve revisión del concepto de discurso (FOUCAULT, 1996, 2008; FAIRCLOUGH, 2003, 2010; MAINGUENEAU, 2008), abordando también los conceptos del dialogismo de Bajtín (2011) y de la inter-incomprensión regulada de Maingueneau (2008). En ese camino, adoptamos como metodología de análisis la teoría social del discurso (FAIRCLOUGH, 2001), y las consideraciones de Blommaert (2005) sobre la naturaleza dialógica de la comunicación. Además, pretendemos establecer el anclaje teórico-metodológico que sirve de norte para nuestro análisis de las muestras de eventos comunicativos. Como resultado del análisis, concluimos que las relaciones inter-discursivas que se realizan en esa sala de aula son controladas entre los participantes de la interacción, de acuerdo con las metas establecidas en el programa del curso, generando una dialogicidad inter-regulada conforme el plan de enseñanza.

Palabras-clave: Discurso. Dialogismo. Sala de aula. Lengua extranjera. 